NEWS

\title{
World looks ahead post-Copenhagen
}

\section{A weak international climate agreement leaves room for science to shape the next round of negotiations.}

\section{COPENHAGEN}

Two lines of evidence nearly brought down the last-minute climate agreement brokered last week in Copenhagen by US President Barack Obama: studies indicating that the impacts of global warming could be more severe than previously thought, and that rich countries could do more to counter the problem without breaking the bank.

Now, negotiators are seeing whether they can strengthen a deal nearly universally acknowledged as weak - or whether even the mounting scientific evidence on the most dire effects of climate change will be enough to forge a more meaningful deal.

The Copenhagen accord, drawn up as a multilateral political agreement between the United States, China, India, Brazil and South Africa, provides a non-binding framework for capturing national commitments that are already on record. Many environmentalists and a number of developing countries criticized it immediately, saying that current climate commitments would not meet the common goal of limiting the increase in global average temperatures to $1.5-2{ }^{\circ} \mathrm{C}$. Indeed, an analysis by the US modelling consortium Climate Interactive estimated that the commitments would result in a temperature rise of $3.9^{\circ} \mathrm{C}$ by the year 2100 .

For its part, the European Union elected in Copenhagen not to increase to $30 \%$ its conditional offer of a $20 \%$ cut in 1990 emissions levels by 2020 . The overall goal remains to hammer out a treaty to replace the 1997 Kyoto Protocol on Climate Change while incorporating climate commitments from developing countries and the United States, which has not ratified the Kyoto agreement.

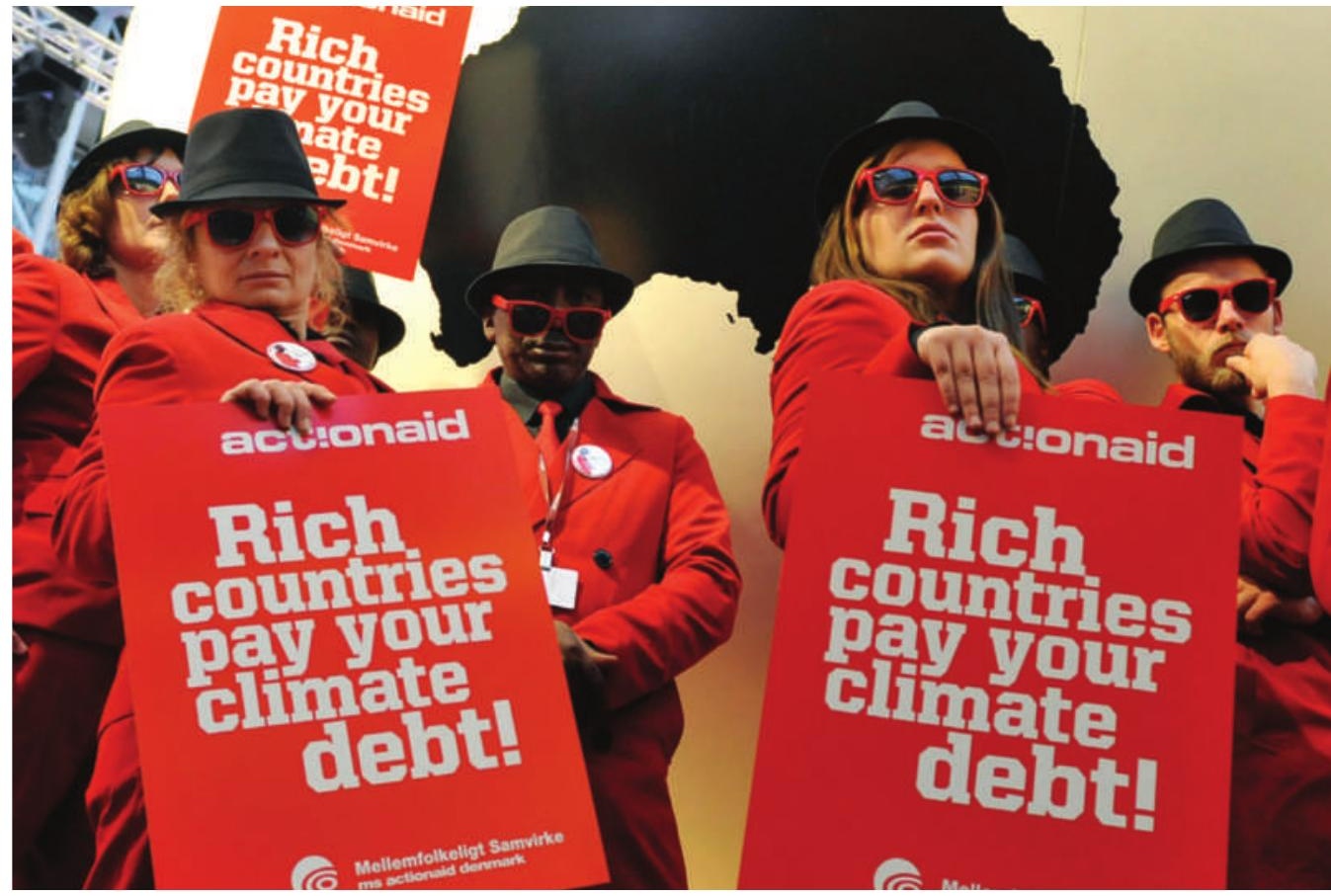

The Copenhagen accord was blasted by environmental activists and leaders of developing nations.

Negotiations will continue over the coming year, and many observers hope for a stronger deal when the parties to the United Nations Framework Convention on Climate Change meet in Mexico in late November 2010.

Obama's announcement on the last day of the Copenhagen talks fractured the G77 group of developing countries. Lumumba Stanislaus Di-Aping, Sudan's fiery chief negotiator and chairman of the G77, claimed that the deal would do nothing less than "destroy"
Africa. He was joined by countries including Tuvalu, Bolivia and Venezuela during an allnight debate that included the occasional tirade against capitalism but also focused on how poor nations would be affected disproportionately by climate change (see 'Growing agricultural benefits for climate'), and how rich countries should be paying more.

For instance, scientists at the Copenhagen meeting had enlisted the star power of Al Gore in releasing a pair of reports on the accelerated

\section{Growing agricultural benefits for climate}

Building on the momentum of using carbon markets to protect forests, scientists are looking at ways to integrate agriculture into climate-change discussions. Better seeds and sustainability practices could make farming more resilient to climate change while increasing yields, cutting emissions and reducing pressure to clear land.

Agricultural practices are responsible for about $15 \%$ of greenhouse-gas emissions but are the main driver of emissions from deforestation. In Copenhagen, negotiators made progress on a programme known as REDD (Reducing Emissions from Deforestation and Forest Degradation). But "if you don't improve agriculture, you'll never get REDD right", says Sandra Brown, a forest-biomass expert with the non-profit organization Winrock International in Arlington, Virginia. Pressure on agriculture will increase in a warming world with more people. A recent study by the United Nations World Food Programme found that shifting precipitation patterns caused by global warming could increase the number of malnourished children by $21 \%$ in 2050 ; some 10 million of those would be in subSaharan Africa. Reporting similar numbers in Copenhagen, scientists with the Consultative Group on International Agricultural Research in Washington DC said that the problem can be addressed by producing better seeds, improving agricultural practices, expanding irrigation and other infrastructure and helping farmers switch to drought-tolerant crops .

"With appropriate expenditures, we can actually address the impacts of climate change," says Thomas Roswell, an ecologist at the Swedish University of Agricultural Sciences in Uppsala. 
loss of glaciers and ice sheets in Greenland and Antarctica; melting ice sheets in particular, they concluded, could increase sea level by at least 1 metre by 2100 .

\section{Easy targets}

Still, an economic analysis by the International Institute for Applied Systems Analysis (IIASA) in Laxenberg, Austria, found that the pre-Copenhagen commitments by industrialized countries would reduce 2020 emissions by $11-22 \%$. Taking into account cost savings due to efficiency and other factors, the cost of achieving that goal would be just $0.15 \%$ of gross domestic product, the analysis revealed. Markus Amann, who heads the IIASA's greenhouse-gas initiative, fears that such easy targets will translate into low carbon prices and end up delaying the innovation needed to make deep cuts in decades to come.

Yet most developing countries ultimately defended the Copenhagen accord - with reservations - because without it there would have been nothing to show for the largest environmental conference in history. "This is not what we have been seeking, but it is a beginning," said Mohamed Nasheed, president of the Maldives, which is a member of the Alliance of Small Island States that has been pushing

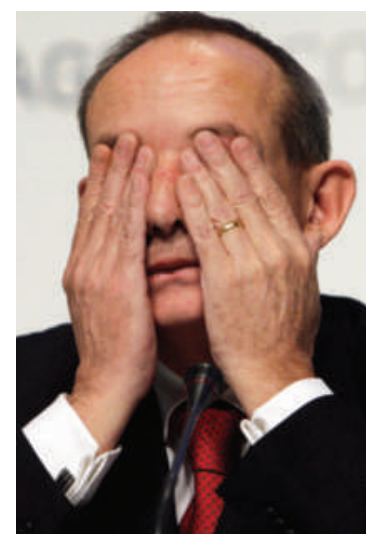

Delegates worked through the night to reach an agreement. ment goals. Developed countries committed to spending upwards of $\$ 100$ billion annually by 2020 , although the agreement offers no details as to where that money will come from. The World Bank has estimated that developing countries will need about that amount, but developing countries and many scientists say that number could be far too low.

Martin Parry of Imperial College London, a former co-chair of the Intergovernmental Panel on Climate Change (IPCC) working group on impacts, adaptation and vulnerability, has developed a way to portray 'unavoided impacts' in which mitigation fails and there isn't enough money to help people cope with the consequences. Assuming that all countries fulfil their pledges, the agreement in Copenhagen still leaves a gap of $1.5^{\circ} \mathrm{C}$, he says. In other words, funding for adaptation could cover impacts associated with about $1.5^{\circ} \mathrm{C}$ of warming, but temperatures are likely to rise by at least $3{ }^{\circ} \mathrm{C}$.

"Even the toughest and most robust measures will not achieve $2{ }^{\circ} \mathrm{C}$," Parry says. "We should hope for $2^{\circ} \mathrm{C}$ but realistically expect $3-3.5^{\circ} \mathrm{C}$, and then plan for $4{ }^{\circ} \mathrm{C}$."

The Copenhagen accord includes a goal of limiting temperature rise to $2{ }^{\circ} \mathrm{C}$, but one target that was notably dropped was that for reducing global greenhouse-gas emissions by 2050. Smallfor a commitment to limit warming to $1.5^{\circ} \mathrm{C}$. "I beg all nations to please back this document and do not let these talks collapse."

"The most important thing to get done at this moment is to get moving," adds John Holdren, Obama's chief science adviser. "Let's not argue for the next five years what the perfect goal is. Let's get going in the right direction."

For the first time under the new framework, both developing and developed countries including the United States, which is gearing up for a legislative battle over climate in the Senate this spring - will be bound under a single agreement. Rich countries would be required to meet their promised reductions; developing countries would be required to audit and report the activities they undertake to reduce emissions, as well as open their books to international verification for any projects funded with international aid.

In exchange, the agreement offers financing, valued at US $\$ 30$ billion by 2012 , to help developing countries prepare for a warmer world and to push forward with sustainable develop- island states successfully pushed for language requiring consideration of a target of $1.5^{\circ} \mathrm{C}$ during the first review of implementation and commitments in 2015, one year after the IPCC is scheduled to finalize its fifth assessment report. Climate modelling for the next IPCC assessment is under way, and the panel will accept nominations and then appoint lead authors for the various chapters this spring.

Sitting in his office overlooking the main hall of the Bella Center in Copenhagen last week, IPCC chair Rajendra Pachauri said that he was encouraged by the fact that so many world leaders chose to attend, even if a commitment to act falls short.

"There's a certain inertia that will resist it. There are mindsets that will resist it. There are vested interests that will resist it - let's not minimize their effectiveness," Pachauri says. "This is something that politically one had to anticipate."

Jeff Tollefson

See Editorial, page 957.

For more, see www.nature.com/

roadtocopenhagen.
REAFFIRMING CLIMATE

\section{SCIENCE}

Climatologists weigh in on hacked e-mails and hockeystick graphs.

go.nature.com/eSCHyE

\section{'Dark-matter' events spotted}

Two sightings in Minnesota have set physicists buzzing about whether the first direct detection of dark matter has been made. If confirmed, it would mark the end of a decades-long search for the mysterious particles thought to make up as much as $85 \%$ of matter in the Universe.

But most agree that the signals are not statistically significant enough to be attributed to dark matter rather than to conventional particles.

The two events were caught in 2007 in super-cooled crystals of germanium and silicon in the underground Cryogenic Dark Matter Search II (CDMSII ) experiment in the Soudan Mine in Minnesota. Last week, CDMSII scientists announced that they have seen candidates for the dark-matter particles known as weakly interacting massive particles (WIMPs), each with a mass of 30-60 gigaelectronvolts - roughly 30-60 times that of a proton.

But from the analysis, team scientists think that there is a $25 \%$ chance that both events might be false-positives caused by background radiation. Those odds are not good enough to claim a definitive detection of WIMPs, says Timothy Sumner, a physicist at Imperial College London. "Statistically, it's not compelling," he says.

"The best we could call it is a hint," adds John Ellis, a theoretical physicist at CERN, Europe's high-energy physics lab near Geneva, Switzerland. "An interesting hint."

The possible detection is the latest in a series of potential dark-matter sightings. In August 2008, an Italian-led satellite-based experiment known as PAMELA reported an excess of antielectrons (positrons) that could have stemmed from the annihilation of darkmatter particles. And in October 2009, NASA's Fermi Gamma-ray Space Telescope saw a haze of high-energy light in the centre of our Galaxy that could be a dark-matter signature.

The CDMSII result will now spur physicists at the Large Hadron Collider (LHC) at CERN to try to generate WIMPs in their collisions. "The LHC would see this very easily and relatively quickly," says Ellis - and could potentially produce a detectable WIMP signal by the end of next year.

Geoff Brumfiel

For a longer version of this story, see go.nature. com/34rnga. 